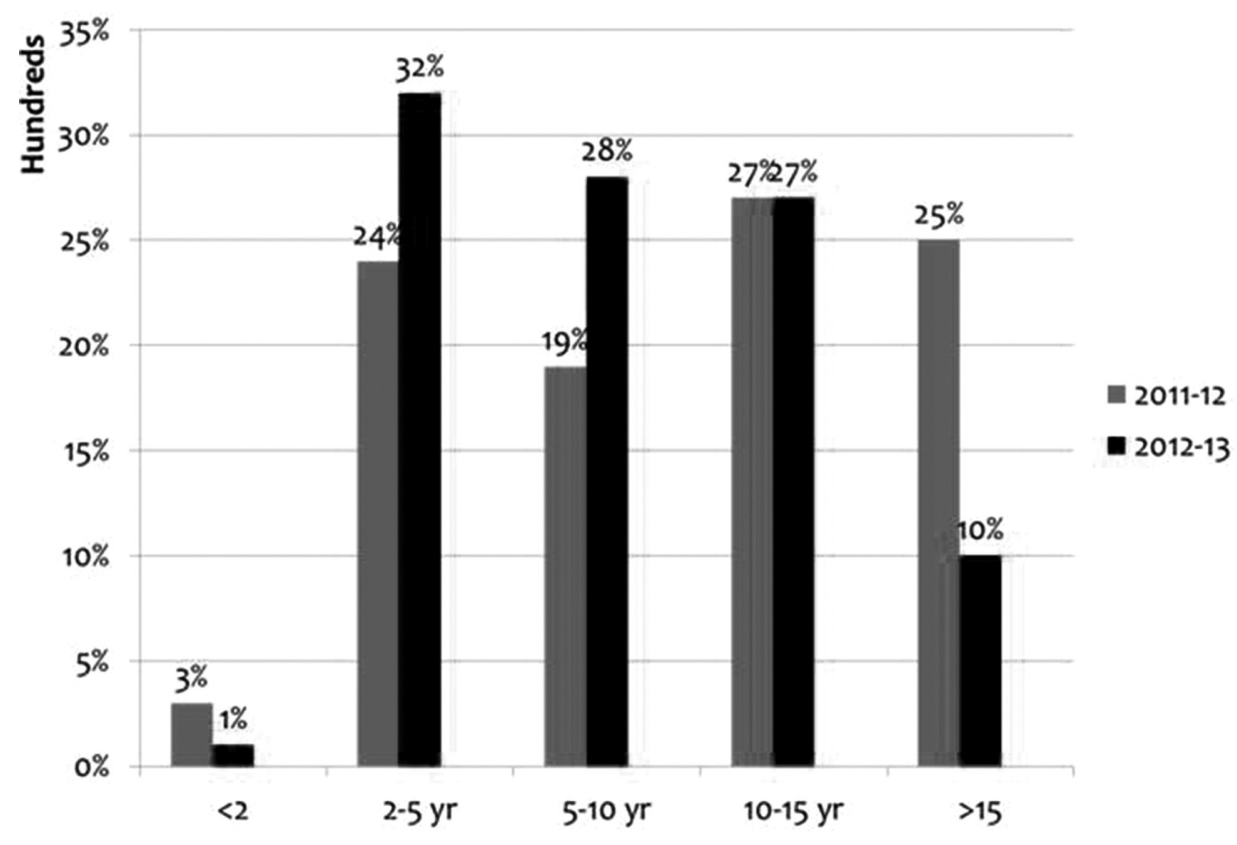

Abstract G51(P) Figure 2 Age distribution

paediatricians' participation. There has been insufficient participation to evaluate learning or impact on outcomes for children. Future options to support participation will be discussed.

\section{G53(P) LISTENING TO CHILDREN AND YOUNG PEOPLE - THE VOICE OF THE CHILD IN CHILD PROTECTION MEDICALS}

${ }^{1} \mathrm{~F}$ Finlay, ${ }^{2} \mathrm{JF}$ Dunne, ${ }^{1} \mathrm{E}$ Hall. ${ }^{1}$ Community Paediatrics, Sirona Care and Health, Bath, UK; ${ }^{2}$ Safeguarding Quality and Patient Safety, NHS Wiltshire CCG, Devizes, UK

\subsection{6/archdischild-2015-308599.52}

Background The RCPCH Child Protection Companion 2013 states 'Record in quotes and verbatim. Record your questions, verbatim'.

Nurses have a long history of acting as advocates for children ensuring that children's and young people's voices are heard in relation to their health, well-being and care.

Children who had experience of the child protection system themselves 'voiced the importance of being heard separately from their parents and being listened to' (Munro, 2011).

Aims To examine whether the voice of the child was being heard and documented in our child protection medical reports.

Method All typed child protection medical reports by community paediatricians from January 2014 to November 2014 for children age 6 and above were examined (excluding child death).

Evidence in reports fell into 4 categories.

Documentation that the entire history was obtained from the child, negating the need for quotation marks.

Dialogue quoting specific questions asked and answers.

Selected quotes from the child.

Descriptive documentation without quotations e.g. child told me..., he explained...

Results 37 medical reports met the criteria. All 37 reports $(100 \%)$ had one form of documented evidence the voice of the child had been heard.
10 of $37(27 \%)$ reports the history was documented as obtained from the child, and within 3 of these there was also quoted dialogue.

2 of 37 reports (5.4\%) contained documented dialogue.

17 of $37(45.9 \%)$ documented selected quotes.

8 of $37(21.6 \%)$ contained descriptive terms only.

Conclusions $100 \%$ of child protection reports examined had documented evidence that we listened to the voice of the child. There is much variability in how we as paediatricians are documenting this.

This variability reflects both the examiner, their experience and personal history taking style, as well as the child, their age, confidence, persons present and simply how much they are willing to share at that time.

There should be more joint working and training between Paediatricians and Children's Nurses to establish secure environments which help children find their voice, specifically in child protection medicals.

\section{G54(P) PAIN IN THE NECK! NON-ACCIDENTAL, NON-LETHAL ATTEMPTED STRANGULATION IN CHILDREN. A DESCRIPTIVE STUDY OF 6 CASES SEEN IN A YEAR}

V Rao. Child Health, Walsall Healthcare Trust, Walsall, UK

\subsection{6/archdischild-2015-308599.53}

Background The neck is a vulnerable part of the body due to its close proximity with major blood vessels, trachea and lack of bony protection. Neck injuries are more likely than not to be non -accidental. $2.5 \%$ of deaths worldwide are by strangulation.

Symptoms in survivors include bruising, hoarse voice, dysphagia, unconsciousness, surgical emphysema and psychological problems in the long term.

There is little literature about non-lethal, non-accidental strangulation injuries in children.

Method Case note review in a 12 month period of 6 children presenting with neck bruising and alleging to being strangled 